\title{
Music Education: A Vehicle for Fostering Positive Youth Development
}

\author{
Ebele V. Ojukwu \\ http://dx.doi./org/10.4314/ujah.v18i2.28
}

\begin{abstract}
In the contemporary Nigerian society, many youths are faced with various challenges. The inability of these young people to cope with these challenges result in all-risk behavior such as lack of confidence, low self-esteem, low motivation, etc. Over the years, indulging in music program has proved to yield positive results in the development of the youths. This paper attempts to investigate the outcome of youth's participation in music programs. The paper argues that active engagement of the youths in music program can yield positive youth development rather than perceived deficits and risks behaviors. The paper is anchored on the positive youth development theory which focused on the positive assets young people bring to their engagement. It employs survey and library as its methodology and concludes by suggesting that since young people who have shown competency in music program exhibit more positive youth development, teaching and learning strategies and environmental supports that foster the development of youths should be emphasized.
\end{abstract}

\section{Introduction}

Younger generation of the society is confronted with all kinds of problems which have led to breakdown of social norms, have led to some feeling marginalized and concerned about their future. Young people unable to cope with the pressures they face resort to all manner of misconducts in the society such as drug addiction, 
dropping out from school, sexual promiscuity, truancy etc. Youths are the foundation of a nation. They are assets and future of a nature. If their development is hampered, the nation suffers severely.

Music is a phenomenon, which has powerful effect in human development. Its influence, capacity and ability cannot be merely restricted to emotions. Dewey (2004) notes that music education supplies the organ of vision which in their fullness represent the concentration and consummation of elements of good which are otherwise scattered and incomplete. Music education is among the oldest arts in existence both in the ancient Western civilization and in Africa. No civilization seems to hold music education in high esteem as the ancient Greece. Several Greek myths attribute to the sound of flute the power of stirring armies into decisive action and to the sound of harp, ability to subdue anger. Music dominated their religious, aesthetic, moral and scientific life.

The primary role of music in ancient Greece is to build character and health. The ancient Greece believed that one must study and understand those subjects that have practical applications to life since they believe that their real worth can be seen in leading the souls out of the ephemeral world of the senses into the unchanging world of the mind. Their educational system included six years training in music believing that the soul ought to learn harmony rhythm and grace (Griffin, 2014). Likewise, in Africa functions of music are culturally emphasized and revolve around all the activities of the day since 'music is integral to the Africans long educational system' (Okafor, 2005:207). Music not only inspires creativity and performance but also seriously impacts overall academic performance. Yudkin (2008) opines that music education 
in the life of a youth forms and regulates ones inclination to life applicability and embraces the noble and the generous to observe decorum, temperance and regularity. The purpose of this study is to $\mathrm{x}$-ray the avenues and the extent through which music education in Nigeria can serve as a vehicle for facilitating youth development and also boost their social change as well. Conceptual definition of the keywords is necessary at this juncture

\section{Music Education}

Most striking definitions of music include that music is an organized sound that is pleasant to the ear; the universal language of the soul that goes beyond the brain and the mind, touching the soul; the central body that organizes the human actions and endeavors. Anything capable of organizing human actions and endavours will most likely lead to positive human development. The philosophy of music education at the tertiary level is to pursue academic excellence in all aspects of musical learning and human endeavour, relating to cultural, social, and economic and development needs of the Nigerian nation. It is expected that students of Music, having learned the Musical art, would be oriented to use such learning in the solution of practical problems confronting them in the society; and would utilize such in the development of the Nigerian culture and environment (Department of Music Hand book, 2014).

Music education is a field of study that deals with the teaching and learning of music in its totality. It covers all the three domains of learning - cognitive, psychomotor and affective (Ramsundar, 2004). In the African context, music education starts from the womb and follows one to the grave. Training in music dates back to pre-colonial era, though, informally and orally transmitted, 
music educates the whole person. Intending musician in any aspect of music serves a period of apprenticeship under an established local performer and understudies the individual for a period of time before he/she could be certified qualified to start plying the trade in music (Ekwueme, 1983; Nketia, 1974). Brown (2013) saw music education as the type of education that enhances the natural abilities such as language development, sounds and words decoding which is necessary for child's development. Involvement with music is considered a fundamental component of human culture and behavior (Yudkin, 2008). Music education delves into all aspects of music teaching and learning at all levels of education, both theoretically, practically, technologically etc. It is a discipline that ensures lots of prospects for its practitioners.

\section{Development}

The word development is a multi dimensional concept. It can be in terms of social, cultural, economical, technological, human, etc. Okpata (2004) defines it as 'multi-dimensional process, involving the organization and re-orientation of the entire economic and social system... improvement of income and output, radical change in institutional, social and administrative structures as well as in popular attitudes, customs and beliefs (p. 169)'.Generally, there are two broad conceptions of development : Physical development and human development. The physical development can be seen in terms of progressive improvements on material conditions of a state or in terms of basic material needs of the people while human development refers to steady improvement on the human values which include all the indices with which the networks of the people's social life are woven and cemented. It also can be viewed in terms of qualitative improvements on people's minds and attitudes (Ideyi, 2008). Both physical and 
human development can be either progressive or retrogressive but in whichever way it involves some sort of movement.

\section{Youth}

Youth is the time of life between childhood and maturity. Encyclopedia Britannica Library defines youth as, 'the time of life when one is young; especially the period between childhood and maturity; the early period of existence, growth, or development the period of life in which one passes from childhood to maturity'. It is a period of rapid changes and increased independence in adolescence which is marked with several physical changes by which their bodies eventually become adult bodies that are capable of reproducing (Ojukwu, 2014). Research has shown that youths constitute three quarter of Nigerian population ranging from the age bracket of $15-35$ in other words; they constitute a significant and growing percentage of Nigeria.

Youth development is a process that prepares a young person to meet the challenges of adolescence and adulthood and achieve his/her full potential. It is a process of growing up and developing ones capacities in positive ways. It is promoted through activities and experiences that help youths develop social, ethical, emotional, physical and cognitive competencies (http://www.nasetalliance.org). This typically takes place in the context of the family, the peer group, the school and the neighborhood or community.

\section{Music Education Programme in Nigeria}

The advent of Christianity and its attendant system of education saw to the introduction of the Western system of education in 
Nigeria and music education was added into the subjects taught in schools beginning from preschool through post-secondary. Since then, the curriculum of music education in Nigeria has undergone several changes all in the bid to make it more functional and serve the intended purpose of empowering and facilitating human and material development among other things.

In the lower education level (primary and junior secondary school), Nigerian music curriculum is divided into three stages namely: lower basic education curriculum for primaries 1-3, middle basic education for primaries 4-6 an upper basic education curriculum for junior secondary 1-3. In these three levels, music education is structured as a part of cultural and creative arts education and it is meant to be a core and compulsory subject throughout these levels of education. At this level, it is expected that every learner who has successfully completed the nine years of continuous basic education schooling should have acquired appropriate levels of literacy, manipulative and life-long skills as well as ethical, moral and civic values needed for laying a solid foundation for life-long musical learning (Nwachukwu, 2012).

This is followed by three years of senior secondary schooling where a student is free to choose whether to offer music as a subject of study. This level of music education is to strengthen further the foundations of manipulative, ethical, moral and civic values acquired at the basic education level. The curriculum of the senior secondary school of which music is grouped under humanities is structured in thematic form while spiral approach is adopted for content organization so that on graduation, every student would have acquired at least one functional trade and thus become functionally useful to himself / herself and the society at 
large. The senior secondary curriculum also prepares the students for higher education for those who desire to proceed further. The philosophy of senior secondary education according to Nwachukwu (2012) implies:

Every learner who has successfully completed the three years of senior secondary school education should have been well prepared for higher education as well as acquired relevant functional trade / entrepreneurship skills needed for poverty eradication, job creation and wealth generation; and in the process strengthened further the foundations for ethical, moral and civic values acquired at the basic education level (p. 12).

At the tertiary level of education, music becomes an area of specialty for candidates who applied to study music as a course of study and only those that scaled through the huddles of admission are admitted in the department of music. The higher institution according to Chiegboka, (2012):

It is an environment for higher education and also a veritable tool for sustainable human and material development and should within the wider human society endavour to participate in the social transformation, economic modernization and the training and upgrading of the total human resources of the nation and for the individuals to see to their formation in character and learning (p.3). 
This is also evidenced in the objectives of the Department of Music, Nnamdi Azikiwe University, Awka which include the following:

- To provide students with adequate knowledge, skills and understanding of Music and related functional disciplines.

- To prepare students as professional Music teachers for the country's educational system.

- To produce high caliber of music graduates who can pursue further studies in Music.

- To prepare students for varied music positions in private and public agencies of our present era of high technology and computerization. Such agencies include the Advertising Agency, the Radio and Television Houses, the Recording Houses, the Media Houses, Cinema, Film, Archives and cultural Divisions, Police, Army and Air Force Bands, Churches and Mosques and so on (www.unizik.edu.ng/arts/music ).

Using the Department of Music, Nnamdi Azikiwe University, Awka as a reference point, Music education in this tertiary institution offers a lot of opportunities for youths who want to harness their creative abilities. Various courses are offered in music and the outcome of students involvement in these courses become veritable tools for sustaining their human and material development within the wider human society as they endavour to participate in the social transformation, economic modernization and the training and upgrading of the total human resources of the nation and for these students to see to their formation in character and learning (Chiegboka, 2012). The courses are designed to develop the individual psychologically, socially, economically, 
culturally, etc, thereby developing the entire person. It is among the few disciplines that are vast enough to give every person opportunity to excel in any aspect of creative human endavour one deemed fit. It opens the mind of the student towards better understanding of the environment around which he lives, appreciates and purposefully key into areas of interest for individual development and economic benefits. Studies investigating the musical and extra-musical benefits of music engagement for young people provide evidence of positive cognitive, emotional and social benefits from music participation. This is evidenced in the various courses offered in the Department of music especially in the ensemble performance studies which gives every student opportunity to express oneself as deemed fit.

\section{Ensemble Performance Studies in Nnamdi Azikiwe University, Awka}

Ensemble performance is one of the areas that record conspicuously a tremendous artistic progression and development in the life of students of the Department of Music Nnamdi Azikiwe University, Awka. An ensemble is a group of performers aiming to achieve a common purpose. The ensemble performance in the Department of Music, Nnamdi Azikiwe University, Awka is one of the courses that must be offered by the students in partial fulfillment for the requirements for the award of B.A. degree. The course since its inception has offered a wonderful avenues for students to showcase their creative potentials at different levels. It is this cohesive and harmonious effort of the group that is the focal point in the ensemble performance which has led to continuous transformation and things continues changing for better leading to great youth development. The musical artistry has continued to nurture and giving attention in contemporary times. This can be 
evidenced in the theory and practice of musical arts at different levels in various Departments of Music spanning round Nigeria. Now the trend has changed in the departments of music for good and continued to reform rapidly. More groups continued springing up as students were encouraged to form more groups where participation is voluntary as obtainable from most African performing groups, giving the students opportunity to belong to any group they deem fit. Nketia (1982 rightly observes, 'in African societies, participation in music may be a voluntary activity or an obligation imposed by one's membership in a social group' (p. 3). There are eight groups namely:

- Western chorus;

- Western orchestra;

- Pop Stage band;

- Pop choreography;

- African chorus;

- African orchestra;

- African opera; and

- African dance.

\section{Western Chorus}

This group entails singing in a choral setting. Here the students are grouped into various singing parts namely, soprano, alto, tenor and bass. The ladies are usually part of the soprano and alto singing parts while the boys make up the tenor and bass parts. Aside gender considerations which help in grouping the students to suitable parts, voice range is the major determinant of which part a student goes to. This group meets at least twice a week for 
rehearsals. The Western chorus group is expected to come up with one hymn, anthem and chant, all in Western choral music style.

\section{Western Orchestra}

This group is intended to train the students to be able to perform at least one Western orchestral instrument as well as perform with other instrumentalists in an orchestral setting. The group is further divided into strings, woodwinds, brass, and sometimes percussive and keyboard instruments are employed in certain renditions. The Western orchestra group is permitted to arrange folk tunes and tunes that reflect the ideals, idioms and idiosyncrasies of the Nigerian environment and several of such pieces have been performed. They are often advised to arrange pieces that will be useful for the events within and outside the university environs. This group meets at least twice a week for rehearsals.

\section{Pop Stage Band}

This group performs pop music ranging from current Nigerian hip pop, old school of the 70s, 80s, and 90s, to Western pop music. Often the group's performance goes along with dance and drama that will help project the performance and the message inherent in it. Most students love to belong to this group and their performances are usually electrifying. One can easily understand the popular appeal that is ascribed to pop music performances since it addresses popular issues and speaks in popular, street slangs showcasing the glamorous lifestyle of pop musicians.

\section{Pop Choreography}

This group performs various dance styles symbolically telling stories from various African and Western cultures. They try to 
rouse the curiosity of the audience who anxiously view the performance with eagerness in order not to miss the sequence of the story being portrayed through the dance

\section{African Chorus}

This group is expected to perform the choral music composed in African style. Given that many African ethnomusicologists have composed several songs in this genre, there is a wide range of repertoires to choose from. This group requires all that the Western chorus entails except that the style of music performed is typical African style of rendition.

\section{African Orchestra}

Here the students are expected to show proficiency in performing African musical instrument. The group understudies different traditional African orchestral group and brings on stage what they have learnt. They are expected to be free to add their own creative ingenuity to the performance as is obtainable in the African traditional performance setting. Traditional ensembles like the Igbammanwu, Igbaegwuregwu, Igbaeze, Egwuabiriba amongst others have been studied and performed by this group in the past.

\section{African Opera}

This group brings to stage, performances of African folk operas. Students are expected to act, sing and sometimes dance, depending on the piece that is required at a certain semester.

\section{African Dance}

This group often performs along the African orchestral group. They are expected to understudy an African dance group and present what they have learnt in the exam. This is part of the 
conscious attempt made to inculcate the aesthetics of the African cultural arts in Nigerian music students

The group leaders of the various groups are charged with the responsibility of keeping order during the rehearsal, coordinating every other affair of the group and keeping record of the attendance for the rehearsals. Punctuality to rehearsals is as important as attendance to such rehearsals. This is so because one person's absence or lateness can hinder the effectiveness of the general output by the group. Each student's performance is judged by the result of the attendance data of the group he or she belongs to and the actual performance on stage is equally vital in the adjudication process. Costuming is of essential importance to these groups hence each group comes up with the costume that fits its performance best.

The performance of each group is judged by the lecturers who expect nothing less than a highly artistic output from each group. This is to make bare the aim for instituting the ensemble studies which entails equipping students with the discipline required in performing with other musicians in a group. One can then observe that the students, by participating and performing in these various groups have been prepared effectively to organize concerts, perform with various other group of musicians, teach the younger generation how to perform in group, raise various performing groups, engage effectively in adjudication of music related events, etc.

The involvement and the collaborative efforts of the students in these performances are highly commendable as they are impressive and they make cogent efforts every semester to improve on their earlier performance. These Students' enthusiastic approach and 
exhibit of commitment in the ensemble performances portray their collaborative creativity as Nwamara (2012) rightly observes, 'collaborative creativity is not new in the traditional musical setting of the Igbo people of Nigeria. Any musical group consisting of more than one person collaborates in one way or the other to achieve unity and uniformity in their art' (p. 3). This implies that the Departments of music in the tertiary institutions groom the musicians (youths) who have positively contributed and are still contributing effectively to the musical development of the Nigerian society.

\section{Conclusion and Recommendation}

This paper has tried to establish that music education in Nigeria cuts across every area of life, culture, education and economic barriers, it is the key to creativity and self realization; it disciplines the mind and facilitates development. Music education is very essential in the life of every human being especially, the younger generation. It has helped in the development of humans from time immemorial. Unfortunately, the number of candidates who register to study music in the tertiary institution is not encouraging because most uninformed youths erroneously have the mentality that music education is not needed for one to be music practitioner especially with the insurgence of the hip-hop genre that engulfed many youths around the globe today. Many did not see formal music education as anything to reckon with. The Nigerian society is yet to appreciate the benefits accrue from music education especially in the area of youth development. Leohard and House (1972) maintain that 'music program should be dedicated to the development of musical responsiveness and musical understanding on the part of all pupils in the school. The task of the school music program is to create a favourable musical environment, one in 
which every pupil can undergo the maximum musical growth consistent with ability and his interest' (P. 4). Agu (2012) presents lack of trained manpower, instructional materials and inadequate support on the part of government as stumbling blocks to achieving proper music education. The government and school authority's' seemly disdain for music as an equally valuable discipline of study has further led to low allocation of fund to it. Furthermore, the society is still grappling from the bad name given to early popular musicians who were looked down on as the wayward, lazy, school dropout, etc in the society and these tags have so much discouraged the youths from taken up career in music as a discipline. Youths should be guided to engage in activities they believe provide a sense of autonomy, competence and social engagement and have an increased tendency for self-determined behaviour and are less likely to engage in at-risk behaviours. Youths of Nigeria should be given opportunity to derive maximum benefits from music education to enable them live fulfilling life and contribute to the development of Nigerian society. In this regard, the society, parents, government, teachers, etc have a lot to do towards making music education an avenue for youth development and social change. This paper therefore suggests:

- Re-orientation of the parents, students and school management on the values, prospects and importance of music education in the development of youths and the society. This can be achieved by inviting renowned musicologists to schools on career weeks, parents and teachers association meetings to give talks on the above issue. 
- The government on the other hand should employ qualified, experienced and competent music specialists to teach in schools and also provide them tools needed for the job in terms of instructional materials, musical instruments and other equipment. This will facilitate the development of performing skills of the students at the appropriate levels and provide them opportunities for regular practice.

- The university management should give opportunity to candidates who register music in JAMB and meet the necessary requirements to come in and study and not cutting them off unnecessarily.

\section{Ebele V. Ojukwu}

Nnamdi Azikiwe University, Awka ev.ojukwu@unizik.edu.ng

\section{References}

Agu, D. C. C. (2012). Perpetuating Nigerian musical culture in musical arts education within the threshold of global environment. Journal of Arts and Humanities, 13 (2). 1-5.

Barrett, M. S. \& Bond, N. (2014). Connecting through music: The contribution of a music programme to fostering positive youth development. Research Studies in Music Education 37, (1). 37-54

Brown, L. L. (2013). The benefits of music education. Available @ www.pbs.org Retrieved: $20^{\text {th }}$ June, 2013. 
Chiegboka, A. B. C. (2012). Departmental administration in the university system: The UNIZIK experience. Awka : Fab Anieh.

Department of Music, Nnamdi Azikiwe University, Awka.

Available @ [http://www.unizik.edu.ng/arts/music]

Retrieved: $25^{\text {th }}$ April, 2016.

Dewey, J. (2004). Democracy and education. New York:

Macmillan.

Ekwueme, L. E. N. (1993). Nigerian music since independence.

The Economic and Social Development of Nigeria, 320331.

Ideyi, N. (2008). Democracy and national development: The

Nigerian experience. In J. Eyisi, I. Odimegwu \& A. Asigbo

(Eds.). Paradise in the Arts Celebrating Prof. C. C.

Agbodike, (pp. 735-750). Awka: Fab Educational Books.

Leonhard, C. \& House, R. W. (1992). Foundations and principles of music Education. NewYork: McGraw-Hill.

National Alliance for Secondary Education and Transition.

Available@ http://www.nasetalliance.org Retrieved: $3^{\text {rd }}$ February, 2016.

Nketia, J. H. K. (1974). The music of Africa. New York: WW

Norton and Company inc.

Nwachukwu, O. P. (2012). Understanding the new revised basic education curriculum. Awka: NERDC.

Ojukwu, E. V. \& Esimone, C. C. (2014). Inculcating morals in adolescents through the Igbo folk music. The 2014 WEI International Academic Conference Proceedings New Orleans, USA, Available @ http://www.westeastinstitute,com 162-171.

Okafor, R. C. (2005). Music in Nigerian Society. Enugu: New Generation Books. 
Okpata, F. O. (2004). Public administration, theory and practice: An integrated approach. Enugu: Cheston Agency.

Ramsundar, C. (2004). So what is music education? Available @ http://www.cxc.org. Retrieved: $18^{\text {th }}$ May, 2013.

Yudkin, J. (2008). Understanding music: Upper sadle river. New Jersey: Prentice Hall. 